\title{
Influência de sanificantes nas características físicas e químicas de uva Itália
}

\author{
Effect of sanitizers on the physical and chemical characteristics of 'Itália' grapes
}

\author{
Silvana ALBERTINI ${ }^{1 \star}$, Ana Carolina Almeida MIGUEL ${ }^{1}$, Marta Helena Fillet SPOTO ${ }^{1}$
}

\begin{abstract}
Resumo
O objetivo deste trabalho foi avaliar a influência dos sanificantes dicloroisocianurato de sódio (NaDCC), álcool etílico e hipoclorito de sódio sobre a qualidade de uva Itália, com base nas características físicas e químicas. Cachos de uva Itália colhidos em São Miguel Arcanjo (SP) foram selecionados por tamanho e qualidade, submetidos a tratamentos pós-colheita, por imersão, em solução de álcool etílico (15\%), de dicloroisocianurato de sódio $(200 \mathrm{ppm})$ e hipoclorito de sódio $(200 \mathrm{ppm})$, por 3 segundos e 10 minutos, respectivamente, e mantidos sob condição ambiente $\left(21,2{ }^{\circ} \mathrm{C} ; 69,8 \%\right.$ UR) por 9 dias. Avaliou-se a cada três dias, a porcentagem de perda de peso dos cachos, a taxa de degrana, a coloração, a firmeza, os teores de sólidos solúveis (SS) e de acidez titulável (AT), o ratio (SS/AT) e o pH das bagas. Nas condições do experimento, a maior perda de massa média diária foi encontrada no tratamento com hipoclorito de sódio $(0,7333 \% /$ dia $)$, seguido da testemunha $(0,6163 \% /$ dia $)$, do dicloro isocianurato de sódio $(0,5837 \% /$ dia $)$ e do álcool etílico $(0,5623 \% / d i a)$. As bagas sanificadas com dicloroisocianurato de sódio dihidratado mostraram-se mais escurecidas e amareladas. Não foram verificadas diferenças atribuíveis à sanificação em relação à firmeza, ao $\mathrm{pH}$, aos teores de sólidos solúveis e de acidez titulável e ao ratio. De acordo com os resultados obtidos, concluiu-se que não há efeito do uso dos sanificantes dicloroisocianurato de sódio, álcool etílico e hipoclorito de sódio sobre as características físico-químicas de uva Itália.
\end{abstract}

Palavras-chave: Vittis vinifera; sanificação; conservação; qualidade.

\begin{abstract}
The objective of this work was to evaluate the influence of sodium dichloroisocianurate (NaDCC), ethylic alcohol, and sodium hypochlorite sanitizers, on the quality of 'Itália' grape, based on the physical and chemical characteristics. Clusters of 'Itália' grape harvested in São Miguel Arcanjo (SP) were selected by size and quality and submitted the postharvest treatments by immersion in ethylic alcohol solution (15\% v/v), sodium dichloroisocianurate $(200 \mathrm{ppm})$, and sodium hypochlorite $(200 \mathrm{ppm})$ for 3 seconds and 10 minutes, respectively under ambient room conditions $\left(21.2^{\circ} \mathrm{C} ; 69.8 \% \mathrm{HR}\right)$ for 9 days. The clusters weight loss, tax of degrane, coloration, firmness, contents of soluble solids (SS), and titratable acidity (TA), SS/TA relation and $\mathrm{pH}$ of the berries were evaluated every three days. Under those conditions, the highest daily average mass loss was found in the sodium hypochlorite ( $0.7333 \% /$ day) followed by the non- sanitized clusters ( $0.6163 \% /$ day), sodium dichloroisocianurate $(0.5837 \%$ /day), and ethylic alcohol ( $0.5623 \%$ /day). The berries sanitized with sodium dichloroisocianurate were darker and yellow. The sanification differences regarding firmness, $\mathrm{pH}$, contents of soluble solids and titratable acidity, and SS/TA relation were not verified. From the results it can be concluded that the sanitizers do not influence in the physical and chemical qualities of 'Itália' grape.

Keywords: Vittis vinifera; sanification; conservation; quality.
\end{abstract}

\section{Introdução}

A uva Itália é a mais importante variedade de uva fina comercializada no Brasil. Por se tratar de um fruto perecível, a uva é susceptível à ocorrência de danos de diversas origens (CASTRO et al., 2003).

Para se obter êxito na comercialização de uvas in natura, os frutos devem apresentar boa qualidade em nível de consumidor e as perdas pós-colheita devem ser baixas. No Brasil, essas perdas são elevadas, da ordem de 20 a 95\% (CHOUDHURY; DA COSTA, 2004), e são caracterizadas pela perda de peso, escurecimento da ráquis, amolecimento das bagas, degrana e desenvolvimento de fungos causadores de podridões (CASTRO et al., 2003).

Em uvas, pouco se conhece sobre o efeito da sanificação na redução da deterioração das bagas armazenadas nas condições de mercado.
O cloro nas suas várias formas é o sanificante mais utilizado em alimentos em função do custo e da disponibilidade do produto (SANTOS, 2003). Entretanto, o dicloroisocianurato de sódio (NaDCC), composto clorado orgânico, age da mesma forma que o hipoclorito de sódio (composto inorgânico), porém, devido ao seu processo de fabricação específico para o consumo humano, não possui substâncias indesejáveis e metais pesados, sendo extremamente seguro para o manuseio; além de possuir $65 \%$ de cloro ativo contra $10-12 \%$ do hipoclorito de sódio (MACEDO, 2001).

Esta pesquisa foi realizada visando avaliar a influência dos sanificantes dicloroisocianurato de sódio (NaDCC), álcool etílico $\left(\mathrm{C}_{2} \mathrm{H}_{6} \mathrm{O}\right)$ e hipoclorito de sódio $(\mathrm{NaClO})$, sobre

Recebido para publicação em 10/8/2007

Aceito para publicação em 29/7/2008 (002749)

${ }^{1}$ Escola Superior de Agricultura "Luiz de Queiroz", Departamento de Agroindústria, Alimentos e Nutrição, Av. Pádua Dias, 11, CP 9, CEP 13418-900, Piracicaba- SP, Brasil, E-mail: albertin@esalq.usp.br

${ }^{*}$ A quem a correspondência deve ser enviada 
a qualidade de uva Itália, com base nas características físicas e químicas.

\section{Material e métodos}

Cachos de uva Itália, procedentes da região de São Miguel Arcanjo (SP), colhidos no período de janeiro a abril de 2007, foram transportados em caixas de papelão ao Departamento de Agroindústria, Alimentos e Nutrição da ESALQ/USP, onde foram selecionados por tamanho e qualidade e divididos em quatro lotes, ou seja: testemunha (não sanificada), cachos imersos em solução de NaDCC a 200 ppm, por 10 minutos, cachos imersos em solução de $\mathrm{NaClO}$ a $200 \mathrm{ppm}$, por 10 minutos, e cachos imersos $\mathrm{em}_{2} \mathrm{H}_{6} \mathrm{O}$ a $15 \%$, por 3 segundos. Após esta etapa, os cachos sanificados foram drenados para a retirada da água em excesso, acondicionados em sacolas de polietileno $(312 \times 215 \times 0,5 \mathrm{~mm})$, sendo o conjunto composto de seis cachos dispostos em caixas de papelão, e mantidos sob condição ambiente $\left(21,2 \pm 1,6{ }^{\circ} \mathrm{C} ; 69,8 \pm 19,2 \%\right.$ UR) por 9 dias.

Durante o período de armazenamento, os cachos foram avaliados, a cada três dias, em relação aos parâmetros: a) perda de massa: obtida por meio da pesagem de cada cacho expressa em porcentagem, considerando-se as diferenças entre os pesos iniciais de cada cacho e os pesos após cada época de avaliação; b) degrana natural: quantificada pela determinação do peso das bagas desprendidas naturalmente em relação ao peso do cacho, sendo os resultados expressos em porcentagem (PEREZ; MOMBERG; BAÑADOS, 1989); c) coloração das bagas: determinada com colorímetro Minolta CR 400b e expressos em Luminosidade (L), ângulo hue ou de cor $\left({ }^{\circ} h\right)$ e cromaticidade $(C)$ (MINOLTA CORP, 1994); d) firmeza: determinada em penetrômetro manual com ponteira de $4 \mathrm{~mm}$ e os resultados expressos em Newton (N); e) sólidos solúveis (SS): determinado por leitura em refratômetro (AOAC, 1997); f) acidez titulável (AT): obtida por titulometria com solução de $\mathrm{NaOH} 0,1 \mathrm{~N}$, sendo os valores expressos em gramas de ácido tartárico por $100 \mathrm{~g}$ de suco (INSTITUTO ADOLFO LUTZ, 1985); g) ratio (relação SS/AT): obtido pelo quociente entre SS; e AT; f) pH: determinado em potenciômetro (INSTITUTO ADOLFO LUTZ, 1985).

O delineamento experimental utilizado foi inteiramente casualizado com esquema fatorial $4 \times 4$. Os fatores estudados foram sanificantes (testemunha; dicloro isocianurato de sódio; álcool etílico e hipoclorito de sódio) e tempo de armazenamento ( $0 ; 3 ; 6 ; \mathrm{e} 9$ dias). Foram utilizadas três repetições por tratamento, sendo cada uma composta por um cacho. Os resultados obtidos das análises físicas e químicas foram submetidos à análise de variância pelo teste $F$ e comparação das médias pelo teste de Tukey a 5\% de probabilidade, e os obtidos do acompanhamento da perda de massa foram submetidos à análise de regressão de acordo com o indicado por Gomes (2002).

\section{Resultados e discussão}

Do ponto de vista prático, observou-se significativa perda de massa, a qual ocorreu de forma gradual durante o período de armazenamento e foi influenciada pelos sanificantes utilizados (Tabela 1). A maior perda de massa média diária foi encontrada no tratamento com hipoclorito de sódio $\left(0,7333 \% \cdot \mathrm{dia}^{-1}\right)$, seguida pela perda da testemunha $\left(0,6163 \% \cdot \mathrm{dia}^{-1}\right)$, da encontrada no lote com dicloroisocianurato de sódio $\left(0,5837 \% \cdot \mathrm{dia}^{-1}\right)$ e com álcool etílico $\left(0,5623 \% \cdot \mathrm{dia}^{-1}\right)$. Um dos principais problemas na vida de armazenamento de muitos frutos é a perda de massa, que está relacionada ao tempo de armazenamento e à transpiração. Essa perda ocorre em função da perda de água, resultando não somente em alterações quantitativas, mas também na aparência (murchamento e enrugamento), nas qualidades texturais (amaciamento, perda de frescor e suculência) e na qualidade nutricional (KADER, 2002).

Os valores de perda de massa obtidos foram superiores $(>5 \%)$ aos citados por Kluge et al. (2002), que consideram que as uvas podem perder até $1,20 \%$ de água, sem que haja piora na aparência e comprometimento das características organolépticas. Logo, pode-se dizer que houve perda da qualidade visual das bagas (murchamento), independente do uso ou não de sanificante.

Não houve interferência dos fatores sanificantes e tempo de armazenamento (dias) na luminosidade das bagas (Tabela 2). Verificou-se que as bagas dos cachos sanificados com dicloroisocianurato de sódio foram as que apresentaram os menores valores de luminosidade no terceiro e sexto dias comparativamente aos demais tratamentos e, ao mesmo tempo, foram as únicas que se tornaram escurecidas com o avanço dos dias. Esse é um importante resultado, já que o escurecimento leva à depreciação visual do produto, podendo diminuir sua aceitabilidade pelo consumidor.

O ângulo de cor das bagas não foi afetado pelo período de armazenamento, porém se verificou que o tipo de sanificante utilizado afetou significativamente a coloração (Tabela 3). As bagas do cacho testemunha se caracterizaram pela coloração levemente verde, enquanto que as bagas sanificadas com dicloroisocianurato de sódio se apresentaram amareladas e as tratadas com álcool etílico e hipoclorito de sódio, verdeamareladas.

Embora nos padrões norte-americanos de qualidade a cor da baga não seja considerada um requisito nas variedades de uvas brancas (CARRARO; CUNHA, 1994) como a variedade Itália, em geral os consumidores associam a coloração predominantemente amarelada às frutas mais maduras, evitam adquirir as frutas "verdes" (ácidas) e preferem as uvas verde claras às verde amareladas. Neste trabalho, constatou-se que todos os tratamentos, exceto a testemunha, enquadraramse na preferência de compra ao longo de todo o período de

Tabela 1. Evolução da perda de massa fresca pelos cachos de uva Itália sanificados e armazenados sob condição ambiente $\left(21,2 \pm 1,6{ }^{\circ} \mathrm{C}\right.$; $69,8 \pm 19,2 \%$ UR).

\begin{tabular}{lc}
\hline \multicolumn{1}{c}{ Tratamentos } & Equações de perda de massa fresca \\
\hline Testemunha & $\mathrm{Y}=0,0290+0,6163^{* *} \mathrm{X} ; \mathrm{R}=0,9996$ \\
Dicloroisocianurato de sódio & $\mathrm{Y}=0,0660+0,5837^{\star *} \mathrm{X} ; \mathrm{R}=0,9960$ \\
Álcool etílico & $\mathrm{Y}=0,1870+0,5623^{* *} \mathrm{X} ; \mathrm{R}=0,9941$ \\
Hipoclorito de sódio & $\mathrm{Y}=-0,3200+0,7333^{\star * X} \mathrm{R}=0,9920$ \\
\hline
\end{tabular}

$\mathrm{Y}=\%$ da massa inicial; $\mathrm{X}=$ dias de armazenamento; $\mathrm{e}^{* *} \mathrm{t}$ significativo a $1 \%$ de probabilidade. 
Tabela 2. Luminosidade (L) em uvas Itália sanificadas e armazenadas sob condição ambiente $\left(21,2 \pm 1,6^{\circ} \mathrm{C} ; 69,8 \pm 19,2 \%\right.$ UR).

\begin{tabular}{|c|c|c|c|c|}
\hline \multirow[t]{2}{*}{ Tratamentos } & \multicolumn{4}{|c|}{ Tempo de armazenamento (dias) } \\
\hline & 0 & 3 & 6 & 9 \\
\hline Testemunha & $41,15^{\mathrm{abA}}$ & $42,01^{\mathrm{aA}}$ & $39,04^{\mathrm{bAB}}$ & $39,98^{\mathrm{abA}}$ \\
\hline Dicloroisocianurato de sódio & $41,67^{\mathrm{aA}}$ & $38,46^{\mathrm{bB}}$ & $37,75^{\mathrm{bB}}$ & $37,68^{\mathrm{bA}}$ \\
\hline Hipoclorito de sódio & $41,30^{\mathrm{aA}}$ & $40,30^{\mathrm{aAB}}$ & $40,19^{\mathrm{aA}}$ & $39,83^{\mathrm{aA}}$ \\
\hline
\end{tabular}

Médias seguidas de pelo menos uma letra comum, minúscula nas linhas e maiúscula nas colunas, não diferem significativamente entre si, pelo teste de Tukey ( $\mathrm{p}<0,05$ ).

Tabela 3. Ângulo de cor $\left({ }^{\circ} h\right)$ e cromaticidade $(C)$ em uvas Itália sanificadas e armazenadas sob condição ambiente $\left(21,2 \pm 1,6{ }^{\circ} \mathrm{C}\right.$; $69,8 \pm 19,2 \%$ UR).

\begin{tabular}{|c|c|c|}
\hline Fator & oh & $\mathrm{C}$ \\
\hline \multicolumn{3}{|l|}{ Tratamento } \\
\hline Testemunha & $118,60^{\mathrm{A}}$ & $11,19^{\mathrm{A}}$ \\
\hline Dicloroisocianurato de sódio & $115,86^{\mathrm{B}}$ & $11,74^{\mathrm{A}}$ \\
\hline Álcool etílico & $116,91^{\mathrm{AB}}$ & $10,87^{\mathrm{A}}$ \\
\hline Hipoclorito de sódio & $117,58^{\mathrm{AB}}$ & $11,51^{\mathrm{A}}$ \\
\hline \multicolumn{3}{|l|}{ Dias } \\
\hline 0 & $117,01^{\mathrm{A}}$ & $11,61^{\mathrm{A}}$ \\
\hline 3 & $116,92^{\mathrm{A}}$ & $11,19^{\mathrm{A}}$ \\
\hline 6 & $117,31^{\mathrm{A}}$ & $11,16^{\mathrm{A}}$ \\
\hline 9 & $117,71^{\mathrm{A}}$ & $11,35^{\mathrm{A}}$ \\
\hline $\mathrm{CV}(\%)$ & 2,05 & 11,10 \\
\hline
\end{tabular}

$h^{o}=$ ângulo de cor; $C=$ cromaticidade. Médias para cada fator, seguidas de pelo menos uma letra comum, nas colunas, não diferem significativamente entre si, pelo teste de Tukey $(\mathrm{p}<0,05)$.

armazenamento, uma vez que se caracterizaram pela coloração verde amarelada.

A cromaticidade $(C)$ não foi influenciada pelos sanificantes, nem pelo período de armazenamento, indicando que não houve alteração na intensidade da cor das bagas, ou seja, na síntese de pigmentos (Tabela 3 ). Isto pode influenciar o poder de compra do consumidor, visto que a aparência é um dos fatores mais importantes para a aquisição de um determinado vegetal nas gôndolas dos supermercados (MATTIUZ; DURIGAN, 2001).

Em relação à degrana natural, verificou-se que as maiores perdas por degrana ocorreram na testemunha $(2,28 \%)$, seguida dos sanificados com hipoclorito de sódio $(1,95 \%)$ e dos higienizados com álcool etílico $(1,85 \%)$ ao $9^{\circ}$ dia de armazenamento. Nas uvas sanificadas com dicloroisocianurato de sódio não foi constatada degrana durante todo o período de armazenamento. Castro, Park e Honório (1999) encontraram taxa de degrana da ordem de 2,35\% em uva Itália mantida sob refrigeração após 14 dias de armazenamento, cujos valores são superiores aos obtidos neste trabalho. Este é um dado importante, uma vez que um índice de degrana superior a $10 \%$ constitui um fator limitante para uma conservação prolongada e representa um problema de qualidade da uva destinada à exportação.

Os valores médios de $\mathrm{pH}$ encontrados variaram de 3,74 a 3,86 (Tabela 4), indicando que a uva é uma fruta ácida $(\mathrm{pH}<4,0)$. Os sanificantes testados não influenciaram o $\mathrm{pH}$ natural da fruta, haja vista que as uvas higienizadas apresentaram valores semelhantes aos da testemunha. Entretanto, o fator tempo de armazenamento apesar de ter promovido alterações estatisticamente significativas nesta variável, são consideradas irrisórias do ponto de vista prático. As pequenas variações no $\mathrm{pH}$ durante o armazenamento possivelmente ocorreram devido ao efeito tampão exercido pelo fluido celular (BEERLI; VILAS BOAS; PICCOLI, 2004).

Não houve efeito significativo da sanificação sobre a firmeza das bagas, porém, com o avanço do período de armazenamento, houve redução da resistência, indicando amolecimento (Tabela 4). Estes resultados refletem o efeito da expressiva perda de massa (transpiração) observada com o avanço dos dias. A perda de firmeza é um evento que comumente ocorre em frutas e tem sido atribuído à modificação nas estruturas e na composição da parede celular pela ação de enzimas (CHITARRA, 2000).

Os teores de sólidos solúveis das uvas apresentaram pequena variação, ou seja, mantiveram-se entre 14, 13 e 15, $63^{\circ}$ Brix. Pequenas variações também foram observadas por Detoni et al. (2005) em uvas Niágara Rosada após 9 dias de armazenamento a $24^{\circ} \mathrm{C}$. Não se observaram diferenças atribuíveis à sanificação e ao tempo de armazenamento, mostrando que estes fatores não afetaram o conteúdo de sólidos solúveis das uvas (Tabela 4). De acordo com os resultados encontrados, pode-se dizer que todas as uvas utilizadas neste trabalho atendem às normas internacionais de comercialização para as uvas de mesa, as quais exigem o teor mínimo de SS de 14 a 17,5 ${ }^{\circ}$ Brix (BARROS; FERRI; OKAWA, 1995; KADER, 2002).

Todos os tratamentos, independente da utilização ou não de sanificantes, não apresentaram diferenças significativas entre si quanto à acidez, ao longo do período de armazenamento (Tabela 4). Resultados semelhantes foram encontrados por Detoni et al. (2005) em uva mantida sob condição ambiente. A manutenção dos teores de acidez titulável pode ser um indicativo de que, na condição de armazenamento empregada $\left(21,2^{\circ} \mathrm{C}\right)$, o metabolismo das uvas permaneceu quase inalterado, ou com pequenas transformações, porém sem causar grandes variações nos resultados.

A manutenção dos teores de sólidos solúveis e de acidez titulável ao longo do armazenamento pode ser justificada devido ao padrão respiratório não climatérico, ou seja, após o amadurecimento, a uva, para de acumular sólidos solúveis e tem seu metabolismo reduzido (CHITARRA; CHITARRA, 2005; YAMASHITA et al., 2000).

A relação entre os teores de sólidos solúveis e de acidez titulável (SS/AT) não foi influenciada por nenhum dos fatores estudados, ou seja, sanificação e período de armazenamento, o que já era esperado dada a manutenção dos conteúdos de 
Tabela 4. Valores médios das características físicas e químicas de uvas Itália sanificadas e armazenadas em temperatura ambiente $\left(21,2 \pm 1,6^{\circ} \mathrm{C}\right.$; $69,8 \pm 19,2 \%$ UR).

\begin{tabular}{|c|c|c|c|c|c|}
\hline Fator & $\mathrm{pH}$ & Firmeza & SS & AT & SS/AT \\
\hline \multicolumn{6}{|l|}{ Tratamento } \\
\hline Testemunha & $3,82^{\mathrm{A}}$ & $25,51^{\mathrm{A}}$ & $14,45^{\mathrm{A}}$ & $0,47^{\mathrm{A}}$ & $34,44^{\mathrm{A}}$ \\
\hline Dicloroisocianurato de sódio & $3,81^{\mathrm{A}}$ & $25,43^{\mathrm{A}}$ & $15,43^{\mathrm{A}}$ & $0,42^{\mathrm{A}}$ & $36,62^{\mathrm{A}}$ \\
\hline Hipoclorito de sódio & $3,74^{\mathrm{A}}$ & $25,67^{\mathrm{A}}$ & $14,45^{\mathrm{A}}$ & $0,45^{\mathrm{A}}$ & $33,11^{\mathrm{A}}$ \\
\hline \multicolumn{6}{|l|}{ Dias } \\
\hline 6 & $3,77^{\mathrm{AB}}$ & $24,53^{\mathrm{BC}}$ & $14,87^{\mathrm{A}}$ & $0,42^{\mathrm{A}}$ & $35,38^{\mathrm{A}}$ \\
\hline 9 & $3,81^{\mathrm{AB}}$ & $23,01^{\mathrm{C}}$ & $14,72^{\mathrm{A}}$ & $0,42^{\mathrm{A}}$ & $35,13^{\mathrm{A}}$ \\
\hline $\mathrm{CV}(\%)$ & 2,58 & 11,97 & 9,79 & 11,65 & 17,44 \\
\hline
\end{tabular}

Firmeza (N); SS = Sólidos Solúveis ( ${ }^{\circ}$ Brix); AT = Acidez Titulável ( $\mathrm{g}$ ác. tartárico. $100 \mathrm{~g}^{-1}$ ). Médias seguidas de pelo menos uma letra comum, na coluna, não diferem significativamente entre si, pelo teste de Tukey $(\mathrm{p}<0,05)$.

açúcares e de acidez, o que resultou em uma relação SS/AT semelhante. O sabor das frutas é devido, em grande parte, ao balanço de ácidos e açúcares, o qual é avaliado pela relação $\mathrm{SS} / \mathrm{AT}$, sendo que um elevado valor desta relação é considerado desejável pelo mercado interno (THÉ et al., 2001). O equilíbrio entre os teores de açúcares e ácidos ao longo do período de armazenamento nas uvas permite inferir que estas apresentaram manutenção da qualidade organoléptica.

\section{Conclusões}

Não há efeito do uso dos sanificantes dicloroisocianurato de sódio, álcool etílico e hipoclorito de sódio sobre as características físico-químicas de uva Itália.

\section{Referências bibliográficas}

Association of Analytical Chemists International - AOAC. Official methods of analysis. $16 \mathrm{ed}$. Washington, 1997.

BARROS, J. C. S. M.; FERRI, C. P.; OKAWA, H. Qualidade da uva fina de mesa comercializada na Ceasa de Campinas, 1993-94. Informações Econômicas, v. 25, n. 7, p. 53-61, 1995.

BEERLI, K. M. C.; VILAS BOAS, E. V. de B.; PICCOLI, R. H. Influência de sanificantes nas características microbiológicas, físicas e físicoquímicas de cebola (Allium cepa L.) minimamente processada. Ciência e Agrotecnologia, v. 28, n. 1, p. 107-112, 2004.

CARRARO, A. F.; CUNHA, M. M. da. Manual de exportação de frutas. Brasília: Ministério da Agricultura, do Abastecimento e da Reforma Agrária - FRUPEX/Instituto Interamericano de Cooperação para a Agricultura, 1994. 252 p.

CASTRO, J. V. de; PARK, K. J.; HONÓRIO, S. L. Armazenamento e processamento de produtos agrícolas. Revista Brasileira de Engenharia Agrícola e Ambiental, v. 3, n. 1, p. 35-40, 1999.

CASTRO, J. V. de et al. Avaliação da efetividade de geradores de SO2 nacionais na conservação pós-colheita e qualidade de uvas 'Itália'. Engenharia Agrícola, v. 23, n. 1, p. 173-178, 2003.

CHITARRA, M. I. F. Processamento mínimo de frutas e hortaliças. Lavras: UFLA/FAEPE, 2000

CHITARRA, M. I. F.; CHITARRA, A. B. Pós colheita de frutas e hortaliças: fisiologia e manuseio. 2 ed. Lavras: UFLA, 2005.

CHOUDHURY, M. M.; DA COSTA, T. S. Embrapa Semi-Árido. Cultivo da videira. In: Colheita e Pós-Colheita. Pernambuco,
2004. Disponível em:<http://sistemaproducao.cnptia.embrapa. br/FontesHTML/Uva/CultivoVideira/colheita.htm>. Acesso em: 7 agosto 2008.

DETONI, A. M. et al. Uva 'Niágara Rosada' cultivada no sistema orgânico e armazenada em diferentes temperaturas. Ciência e Tecnologia de Alimentos, v. 25, n. 3, p. 546-552, 2005.

GOMES, F. P. Estatística aplicada a experimentos agronômicos e florestais. Piracicaba: FEALQ, 2002.

INSTITUTO ADOLFO LUTZ. Normas Analíticas do Instituto Adolfo Lutz: métodos químicos e físicos para análises de alimentos. São Paulo, 1985.

KADER, A. A. Postharvest biology and technology: an overview. In: __ Postharvest technology or horticultural crops. 3 ed. California: University of California; Agriculture and Natural Resources, 2002. p. 435-461.

KLUGE, R. A. et al. Fisiologia e manejo pós-colheita de frutas de clima temperado. 2 ed. Pelotas: UFPEL, 2002.

MACEDO, J. A. B. Subprodutos do processo de desinfecção de água pelo uso de derivados clorados. Juiz de Fora: [s.n.], 2001.

MATTIUZ, B. H.; DURIGAN, J. F. Efeito de injúrias mecânicas na firmeza e coloração de goiabas das cultivares Paluma e Pedro Sato. Revista Brasileira de Fruticultura, v. 23, n. 2, p. 277-281, 2001.

MINOLTA CORP. Precise color communication: color control from feeling to instrumentation. Ramsey: Minolta Corporation Instrument Systems Division, 1994.

PEREZ, J.; MOMBERG, W.; BAÑADOS, P. Evaluación de algunos factores predisponentes del desgrane o caída seca bayas em postcosecha em uva de mesa del cv. Sultanina (Thompson Seedless). Ciência e Investigación Agrária, v. 16, n. 1-2, p. 75-88, 1989.

SANTOS, H. P. dos. Influência da sanificação sobre a qualidade de melão Amarelo (Cucumis melo L.) minimamente processado. Lavras, 2003. 84 p. Dissertação (Mestrado em Ciência dos Alimentos) - Universidade Federal de Lavras (UFLA).

THÉ, P. M. P. et al. Efeito da temperatura de armazenamento e do estádio de maturação sobre a composição química do abacaxi cv. Smooth Cayenne L. Ciência e Agrotecnologia, v. 25, n. 2, p. 356-363, 2001.

YAMASHITA, F. et al. Influência de diferentes embalagens de atmosfera modificada sobre a aceitação de uvas finas de mesa var. Itália mantidas sob refrigeração. Ciência e Tecnologia dos Alimentos, v. 20 , n. 1, p. 110-114, 2000. 